\title{
Evaluation of Lipid-producing Yeast for Biodiesel Production
}

\author{
Dalia M. Mohammed, Enas A. Hassan", Fatma H. Abd El \\ Zaher, H.K. Abd El Maksoud and E.M. Ramadan* \\ Department of Agricultural Microbiology, National Research \\ Center and *Department of Agricultural Microbiology, Faculty \\ of Agriculture, Ain Shams University, Cairo, Egypt.
}

\begin{abstract}
A TOTAL of 76 yeast isolates were isolated from different sources A included soil, organic manure, rotted fruits and different pickles based on the typical morphological character of yeast using light microscopy. These isolates were screened on their ability to accumulate intracellular lipids within the cells by culturing on nitrogen-limited medium (productive medium) and using Sudan Black B staining technique. Sixty lipid producing yeast isolates were detected. Estimation of biomass, lipid yield and lipid content were done for 33 oleaginous yeast isolates, based on amount of lipid accumulation. Four isolates (S5, D5, J3 and C9) proved to have high lipid levels. The growth parameters ( lipid content, biomass yield, sugar utilization efficiency, conversion coefficient) were determined during the fermentation time under circumstances of N-limitation medium using a shake flask technique. Lipid synthesis was partially associated with both the linear growth phase and during the stationary phase. The fatty acids profile analysis revealed that the lipid extracted from the four promising yeast isolates mainly contained the principal fatty acids (triacylglyceols, TAGs) as palmitic acid (C16:0), stearic acid (C18:0), oleic acid (C18:1) and linoleic acid (C18:2) which is similar to that of vegetable oils. The ratio of saturated and unsaturated fatty acids for the four oleaginous yeasts varied. Isolates S5 and D5 which showed the most potential in lipid production and had similar fatty acid profile to plant oils, were identified as Candida tropicalis and Pichia kudriavzevii respectively using a molecular genetics technique. Finally, the data show that the identified strains of oleaginous yeast are promising as viable producers of biodiesel
\end{abstract}

Keywords: Biodiesel, Lipids-producing yeast, Fatty acid profile, $26 \mathrm{~S}$ rRNA gene.

Due to the energy crisis and environmental concerns, high energy prices and potential depletion of fossil fuel, biodiesel has gained much interest as an alternative renewable energy and a substitute for petroleum diesel fuels. Biodiesel has many advantages, such as inherent lubricity, superior flash point, and biodegradability (Xu et al., 2013). It contributes to the reduction of carbon dioxide from fossil fuels and sulfur emissions to the atmosphere so is considered an environmentally friendly solution for global warming (Meng et al., 2009). Biodiesel consists of monoalkylesters of long-chain fatty acids with short-chain alcohols, primarily methanol and ethanol, resulting in fatty acid methyl esters 
(FAMEs) and/or fatty acid ethyl esters (FAEEs), respectively. In general, biodiesel is produced by transesterification of triacylglycerides (TAGs) with alcohols in the presence of different types of catalysts, such as bases, acids or enzymes (Liu \& Zhao, 2007; Ferella et al., 2010; Cao et al., 2012; Liu et al., 2012 and Fedosov et al., 2013). Conventionally, vegetable oils such as palm oil, soybean oil, rapeseed oil, and sunflower oil have been explored as the feedstock for biodiesel production in many countries (Escobar et al., 2009). However, vegetable oils are relatively expensive, In addition, being a common food staple, vegetable oils may be subject to shortage if a significant amount of the oils are dedicated to biodiesel production.

Oleaginous microorganisms, such as yeasts, fungi, and microalgae, can accumulate high amounts of neutral storage lipids under appropriate cultivation conditions. There is an increasing interest in microbial lipid compounds, called single cell oils (SCO) due to potential biotechnological applications, such food ingredients, antimicrobial activity, and biodiesel production (Papanikolaou et al., 2004; Li et al., 2008; Beopoulos et al., 2009 and Amaretti et al., 2010). Heterotrophic oleaginous microorganisms have gained significant attention : the utilization of this oleaginous biomass has been successfully exploited as a source of triacylglycerides (TAGs) for the production of biodiesel (Liu \& Zhao, 2007; Zhu et al., 2008; Azócar et al., 2010 and Yoo et al., 2010). TAGs that exhibit similar fatty acids (FAs) composition and energy value to plant oils or microbial lipids have also many advantages beside a short life cycle. They can be produced in any location, unaffected by season or climate, are easy to scale-up and can be growen on a variety of substances and thus promise to overcome many limitations of plant oils. Oleaginous yeasts are capable to synthesize and accumulate high amounts of neutral lipids which are stored in specialized intracellular compartments known as lipids bodies (Czabany et al., 2007). Oleaginous yeasts have been reported as good producers of lipids, mostly consisting of TAGs (Rossi et al., 2009). Oleaginous yeast species are highly productive on a per-cell basis, with lipid yields of up to $70 \%$ dry weight and grow to high densities with biomass yields of up to 10 to $100 \mathrm{~g} / \mathrm{l}$ within 3 to 7 days (Angerbauer et al., 2008 and Liu et al., 2008). The most common yeasts so far examined for biofuel production are Rhodotorula glutinis, Yarrowia lipolytica and Lipomyces starkeyii (Angerbauer et al., 2008 and Yen \& Yang, 2012). Appropriate process conditions are required by these organisms to induce lipogenesis and to produce large amounts of storage lipids. The most efficient condition described thus far is growth under nitrogen limitation in the presence of an excessive source of carbon (Granger et al., 1993 and Ratledge \& Wynn, 2002).

The aim of this work was to isolate some oleaginous yeast from different sources and evaluate their ability to produce intracellular triglycerides lipid for biodiesel production.

Egypt. J. Microbiol. 49 (2014) 


\section{Materials and Methods}

Sample collection

Five soil samples collected from fields of different plants grown in various sites in Giza Governorate, samples of sugar cane juice, rotten fruits and pickles from a local market as well as samples of organic manure were collected. The collected samples were packed in plastic bags and transferred to the laboratory in an ice box for yeast isolation.

Isolation of lipid producing yeasts

One gram from each soil or organic manure sample was added in $50 \mathrm{ml}$ of glycerol-enriched medium consisting of $\left(\mathrm{gl}^{-1}\right)$ : glycerol $100 \mathrm{ml},\left(\mathrm{NH}_{4}\right)_{2} \mathrm{SO}_{4} 1.0$, $\mathrm{KH}_{2} \mathrm{PO}_{4} 1.0, \mathrm{MgSO}_{4} \cdot 7 \mathrm{H}_{2} \mathrm{O} 0.5$, yeast extract 0.2 , pH 5.5 in a 250 -ml Erlenmeyer flask, and incubated in an incubator shaker $(150 \mathrm{rpm})$ at $28{ }^{\circ} \mathrm{C}$ for $48 \mathrm{~h}$ (Pan et al., 2009). For isolation of yeasts, $1 \mathrm{ml}$ of the above pre-cultured samples was added to $9 \mathrm{ml}$ of saline solution $(0.9 \% \mathrm{NaCl})$ and 10 -fold serial dilutions were followed. Portions of $1 \mathrm{ml}$ from each dilution were spread onto plates contained medium (I) consisting of $\left(\mathrm{gl}^{-1}\right)$ : glucose 20.0, $\left(\mathrm{NH}_{4}\right)_{2} \mathrm{SO}_{4} 5.0, \mathrm{KH}_{2} \mathrm{PO}_{4} 1.0, \mathrm{MgSO}_{4} \cdot 7 \mathrm{H}_{2} \mathrm{O}$ 0.5 , yeast extract 0.5 , agar 20.0 in presence of $3.3 \mathrm{ml}$ of streptomycin solution (10 $000 \mathrm{U} / \mathrm{ml})$ with an adjusted pH 5.5 (Pan et al., 2009). In the case of different rotten fruits and pickles, $1 \mathrm{~g}$ sample was added to $9 \mathrm{ml}$ saline solution and was streaked onto plates contained the previous medium. The plates were incubated at $28-30^{\circ} \mathrm{C}$ for 2 days, and those containing isolated colonies with the morphology typical of yeasts were used for further study.

\section{Screening for oleaginous yeasts}

The purified yeast cultures were cultivated on nitrogen limited medium (Dai et al., 2007) and after the incubation period, the yeast colonies were further screened for their cellular lipid contents by qualitative analysis with a Sudan Black B Staining technique according to Thakur et al. (1988). Black lipid bodies can be observed with an optical microscope. The pattern of lipid content can be observed by the density of the granules of yeast cells. The results were recorded according to the following criteria:,,,++++++++++ corresponding to less than $20 \%, 20-40 \%, 50-70 \%$ and more than $70 \%$ of cells presenting granules, respectively. The potential oleaginous yeast colonies were maintained on slants of yeast peptone glucose medium (Seki et al., 1985). Yeast isolates with high lipid content were collected and screened further for their lipid production ability quantitatively.

\section{Determination of lipid production in isolated yeast}

Preparation of inoculum

The propagation was carried out in $250 \mathrm{ml}$ Erlenmeyer flasks containing $100 \mathrm{ml}$ broth of medium (I), inoculated with $1 \mathrm{ml}$ standard inoculum $\left(\sim 10^{8} \mathrm{cfu} / \mathrm{ml}\right)$ of each isolate and incubated at $28-30^{\circ} \mathrm{C}$ for 2 days with shaking $(150 \mathrm{rpm})$. 


\section{Procedure technique}

An aliquot of $5 \mathrm{ml}$ of propagation cultures of each tested isolate was transferred into a flask containing $45 \mathrm{ml}$ of nitrogen-limited medium (productive medium), then incubated at $28-30^{\circ} \mathrm{C}$ in a shaking incubator $(150 \mathrm{rpm}$ ) for 5 days (Pan et al., 2009). Duplicate samples were analyzed for dry biomass, lipid weight and lipid content.

\section{Lipid extraction}

Total yeast lipids were extracted according to the procedures described by Folch et al. (1957). After incubation, the yeast cells were harvested by centrifugation at 3,000 rpm for $15 \mathrm{~min}$. The yeast cells were collected and washed twice with distilled water, to be ready for lipid extraction. Approximate 2 grams (wet weight) of the rinsed cells was extracted with $40 \mathrm{ml}$ of mixture chloroform/methanol $(2: 1 \mathrm{v} / \mathrm{v})$ at room temperature for 1 hour. The solvent mixture containing the extracted lipids was separated from the residual biomass by centrifugation and all the fractions from each stage were pooled. The extracted lipids in the chloroform phase were separated from the aqueous phase by addition of $8 \mathrm{ml}$ of saline solution $(0.9 \% \mathrm{NaCl})$ in a separating funnel with stirring vigorously for phase separation. The upper aqueous phase containing water, methanol and non-lipid compounds was discarded and the lower phase (chloroform) was filtered using a filter paper containing $1 \mathrm{~g}$ of anhydrous sodium sulfate. The lipid extract in chloroform was collected into weight-measured glass vials, then the solvent evaporated. After drying, the amount of lipid extracted from each yeast isolate was determined.

\section{Fermentation process of growth and lipid synthesis}

This experiment was constructed to study the growth behavior, lipid production and sugar consumption of the selected yeast isolates individually, on nitrogen-limited medium (Pan et al., 2009). After the incubation period, $100 \mathrm{ml}$ of inoculum, as mentioned previously, was centrifuged at $5000 \mathrm{rpm}$ for $10 \mathrm{~min}$ under aseptic conditions and the sediment cells were washed twice with sterilized distilled water to inoculate the second stage flasks which contained $100 \mathrm{ml}$ of production medium then incubated at $28-30^{\circ} \mathrm{C}$ under shaking conditions (150 $\mathrm{rpm}$ ) for $128 \mathrm{hr}$. Samples were taken periodically to determine the cell dry weight, lipid weight, lipid content, sugar consumed, sugar utilization efficiency and conversion coefficient during cultivation. Growth curves of the selected isolates were carried out by plotting the relation between time (h) and cell dry weight $\left(\mathrm{gl}^{-1}\right)$. Specific growth rate $(\mu)$, doubling time $\left(\mathrm{t}_{\mathrm{d}}\right)$, multiplication rate $(\mathrm{MR})$ and number of generation $(\mathrm{N})$ were also calculated. All tests were performed in triplicates.

Analysis of fatty acid profile

The fatty acids of lipid were estimated as methyl esters according to Luddy et al. (1960) using gas chromatography:(Perkin Elmer Auto System XL) with Capillary Column containing silica ZB-Wax (60 m x $0.32 \mathrm{~mm}$ i.d) and equipped with flame

Egypt. J. Microbiol. 49 (2014) 
ionization detector (FID), Oven temperature was maintained initially at $50^{\circ} \mathrm{C}$ and programmed from 50 to $220^{\circ} \mathrm{C}$ for $2 \mathrm{~min}$, Injector temp. $230^{\circ} \mathrm{C}$, detector temp. $250{ }^{\circ} \mathrm{C}$ and the carrier gas was helium at a flow rate: $1 \mathrm{ml} / \mathrm{min}$. Fatty acid methyl esters were identified and quantified by comparison of their retention time with authentic standards.

Identification of the potential lipid-producing yeast

In order to identify the most efficient yeast isolates, sequence analysis of the variable D1/D2 domain of the large subunit (26S) of ribosomal DNA was performed. The divergent D1/D2 domain of 26S rDNA was amplified with primers NL-1 (5'- GCA TAT CAA TAA GCG GAG GAA AAG-3') and NL4 (5'-GGT CCG TGT TTC AAG ACG G-3') (Kurtzman \& Robnett, 1998). The polymerase chain reaction (PCR) product was checked by agarose gel electrophoresis. The amplified product was then purified using Gene JET ${ }^{\mathrm{TM}}$ PCR purification Kit (Thermo) and sequenced by GATC Company (Germany). The $26 \mathrm{~S}$ sequence of the isolated yeasts was used for a BLAST search in the EMBL/Gen Bank database. Identification was based on the Kurtzman \& Robnett (1998) statement that yeast strains showing nucleotide substitutions greater than $1 \%$ in the D1/D2 domain of the LSU rRNA gene were usually different species.

\section{Phylogenetic relationships}

The BLAST database of National Center for Biotechnology Information was used to compare resolved sequences of the most efficient isolates with known 26S rDNA sequences (Altschul et al., 1997). Determination of phylogenetic relationships was analyzed by the program Phylogenetic Analysis.

\section{Statistical analysis}

Statistical analysis (standard error "SE" ) was according to Fisher (1970).

\section{Results and Discussion}

\section{Screening and characterization of oleaginous yeast}

A total number of 76 yeast cultures with morphology typical of yeasts were isolated from different sources. Lipid accumulation capacity of the isolated yeast was revealed by Sudan Black B staining of the cells grown in nitrogen-limited medium (Table 1\& Fig 1). The lipid accumulation process requires the exhaustion of a nutrient, usually nitrogen, to allow excess carbon to be incorporated into lipids (Pan et al., 2009). The preliminary screening of all 76 yeast isolates stained by Sudan Black B exhibited that 33 isolates of yeast were lipid producers, showing good growth and lipid accumulation as seen in Table1. The data demonstrated that the isolates S5,D5,J3 and C9 grew extremely well and accumulated the highest lipid content based on the presence of black particles inside the cell as shown by microscopic examination. 
TABLE 1. Detection of lipid droplets produced by yeast isolates stained with Sudan Black B using microscopic examination.

\begin{tabular}{|l|l|l|c|}
\hline Isolate's code & $\begin{array}{c}\text { Lipid } \\
\text { detection }\end{array}$ & \multicolumn{1}{|c|}{ Isolate's code } & $\begin{array}{l}\text { Lipid } \\
\text { detection }\end{array}$ \\
\cline { 1 - 2 } $\begin{array}{l}\text { S1,S14,S21,S22,S23,D3, } \\
\text { F5, O2 }\end{array}$ & +++ & $\begin{array}{l}\text { S19, S24, G1, J2, J4, Pe1, B1, A1, } \\
\text { Sc1, C2, C3, C7,T1, T2, T4,T5, } \\
\text { O3, On1, On2, Cr1, Cr2, L1, mP2, } \\
\text { mP3 }\end{array}$ & + \\
\cline { 1 - 2 } $\begin{array}{l}\text { S2,S3,S4,S6,S7,S8,S11,S12, } \\
\text { S13, S15, S16, S17, S20, } \\
\text { S25, D1, F1, F3, F6, B2, } \\
\text { C1, C4, C5, C8, O1, O4, } \\
\text { L3 }\end{array}$ & ++ & S9,S10,S18,D2,D4,J1,M1,M2,F2, & \\
\cline { 1 - 2 } S5,D5,J3,C9 & & & - \\
\hline
\end{tabular}

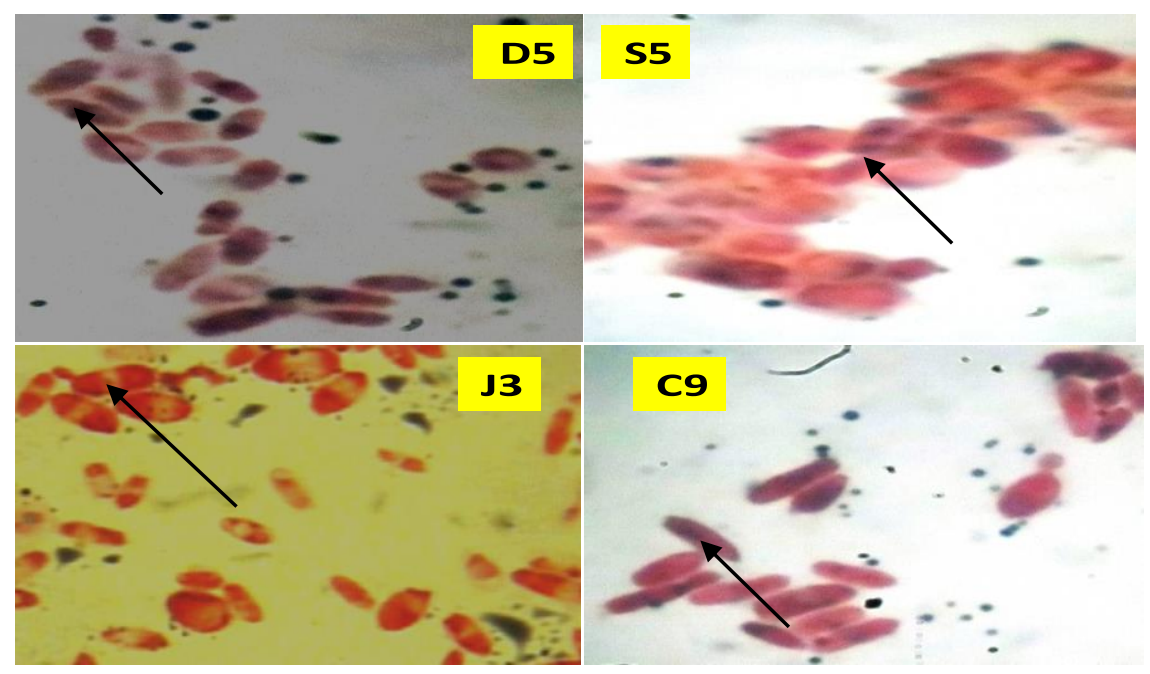

Fig.1. Lipid droplets of yeast isolates D5, S5, J3 and C9 grown on N-limited medium, stained with Sudan Black B as seen under light microscopy $(1700 \mathrm{x})$.

Determination of lipid content

Table 2 shows the quantitative assessment of selected 33 yeast isolates after growth on N-limiting medium by extraction and estimation of cell dry weight, lipid weight and lipid content. Wide variations occurred in all tested parameters between the examined isolates. Among 33 isolates ,four isolates designated S5, D5, J3 and C9 gave the highest potentiality in accumulation of lipids ranging between $0.59-1.24 \mathrm{gl}^{-1}$.The corresponding figures for lipid content $(\%)$ ranged between $18.77-24.47 \%$ respectively. Therefore these isolates were selected for further studies. Many investigators have reported that some yeasts have the ability to accumulate high percentage of lipid globules in their cells such as Rhodotorula glutinis, Yarrowia lipolitica and Lipomyces starkeyii (Angerbauer et al., 2008 and Yen \& Yang, 2012).

Egypt. J. Microbiol. 49 (2014) 
TABLE 2. Quantitative assessment of lipid content for yeast isolates grown on Nlimited medium.

\begin{tabular}{|c|c|c|c|}
\hline Isolates code & $\begin{array}{c}\text { Cell dry weight } \\
(\mathrm{g} / \mathrm{l})\end{array}$ & Lipid weight (g/l) & $\begin{array}{c}\text { Lipid content } \\
(\%)^{*}\end{array}$ \\
\hline S1 & $6.83 \pm 0.056$ & $0.46 \pm 0.02$ & $6.73 \pm 0.29$ \\
\hline S2 & $3.69 \pm 0.29$ & $0.19 \pm 0.03$ & $5.15 \pm 0.29$ \\
\hline S3 & $11.39 \pm 0.29$ & $0.77 \pm 0.03$ & $6.76 \pm 0.29$ \\
\hline S4 & $3.09 \pm 0.29$ & $0.24 \pm 0.02$ & $7.76 \pm 0.29$ \\
\hline S5 & $2.66 \pm 0.29$ & $0.59 \pm 0.03$ & $22.18 \pm 1.15$ \\
\hline S6 & $6.93 \pm 0.29$ & $0.33 \pm 0.017$ & $4.76 \pm 0.11$ \\
\hline S7 & $4.4 \pm 0.23$ & $0.48 \pm 0.03$ & $10.90 \pm 0.26$ \\
\hline S8 & $5.85 \pm 0.26$ & $0.72 \pm 0.12$ & $12.30 \pm 0.29$ \\
\hline S11 & $11.6 \pm 0.29$ & $0.45 \pm 0.02$ & $3.88 \pm 0.29$ \\
\hline S12 & $5.44 \pm 0.26$ & $0.13 \pm 0.01$ & $2.39 \pm 0.23$ \\
\hline S13 & $4.34 \pm 0.29$ & $0.27 \pm 0.03$ & $6.22 \pm 0.29$ \\
\hline S14 & $5.36 \pm 0.17$ & $0.62 \pm 0.06$ & $11.56 \pm 0.58$ \\
\hline S15 & $15.15 \pm 0.58$ & $0.56 \pm 0.03$ & $3.69 \pm 0.29$ \\
\hline S16 & $4.17 \pm 0.29$ & $0.44 \pm 0.02$ & $10.55 \pm 0.58$ \\
\hline S17 & $9.62 \pm 0.29$ & $0.41 \pm 0.06$ & $4.26 \pm 0.58$ \\
\hline S21 & $5.58 \pm 0.29$ & $0.71 \pm 0.12$ & $12.72 \pm 0.29$ \\
\hline S23 & $3.89 \pm 0.29$ & $0.12 \pm 0.01$ & $3.08 \pm 0.58$ \\
\hline D1 & $6.78 \pm 0.29$ & $1.02 \pm 0.29$ & $15.04 \pm 0.58$ \\
\hline D3 & $1.47 \pm 0.29$ & $0.11 \pm 0.00$ & $7.48 \pm 0.58$ \\
\hline D5 & $5.28 \pm 0.44$ & $1.24 \pm 0.29$ & $23.48 \pm 0.29$ \\
\hline F1 & $6.8 \pm 0.29$ & $0.11 \pm 0.00$ & $1.61 \pm 0.29$ \\
\hline F3 & $3.5 \pm 0.29$ & $0.17 \pm 0.03$ & $4.85 \pm 0.06$ \\
\hline F6 & $6.04 \pm 0.29$ & $0.13 \pm 0.03$ & $2.15 \pm 0.58$ \\
\hline $\mathrm{J} 3$ & $6.18 \pm 0.58$ & $1.16 \pm 0.29$ & $18.77 \pm 0.58$ \\
\hline $\mathrm{J} 4$ & $4.14 \pm 0.29$ & $0.32 \pm 0.03$ & $7.72 \pm 0.58$ \\
\hline B2 & $9.48 \pm 0.29$ & $1.47 \pm 0.23$ & $15.50 \pm 0.58$ \\
\hline $\mathrm{C} 1$ & $11.15 \pm 0.58$ & $1.72 \pm 0.29$ & $15.42 \pm 0.58$ \\
\hline C9 & $2.82 \pm 0.29$ & $0.69 \pm 0.17$ & $24.47 \pm 1.15$ \\
\hline $\mathrm{C} 8$ & $8.14 \pm 0.29$ & $0.72 \pm 0.29$ & $8.84 \pm 0.58$ \\
\hline L.3 & $4.25 \pm 0.47$ & $0.14 \pm 0.02$ & $3.29 \pm 0.47$ \\
\hline $\mathrm{O} 1$ & $1.92 \pm 0.29$ & $0.26 \pm 0.03$ & $13.54 \pm 0.29$ \\
\hline $\mathrm{O} 2$ & $4.9 \pm 0.29$ & $0.82 \pm 0.29$ & $16.73 \pm 0.29$ \\
\hline On2 & $11.21 \pm 0.58$ & $0.53 \pm 0.02$ & $4.72 \pm 0.29$ \\
\hline
\end{tabular}

${ }^{*}$ Lipid content \% $=$ lipid weight $\left(\mathrm{gl}^{-1}\right) /$ cell dry weight $\left(\mathrm{gl}^{-1}\right) \times 100$

Results are expressed as the means \pm standard error of three replicates. 
Time course of biomass production and lipid accumulation

Data presented in Fig. 2 show the correlation between growth development of the isolates S5, D5, J3 and C9 grown in nitrogen-limited medium during $128 \mathrm{~h}$ of fermentation. Growth development was determined by the dry weight of cell mass $\left(\mathrm{gl}^{-1}\right)$ in a semi-logarithmic scale. It is obvious that the exponential phase of growth lasted for about $24 \mathrm{~h}$ of incubation, whereas the stationary phase occurred during 24-120 hr for isolates D5, J3, C9 and from 24-104 h for isolate S5. High positive correlation coefficient was observed between the cell dry weight $\left(\mathrm{gl}^{-1}\right)$ and time of incubation period (h) with all tested isolates. Some parameters of growth were calculated during exponential phase presented in Table 3 . The highest value of specific growth rate $(\mu)$ was recorded by S5 $\left(0.089 \mathrm{~h}^{-1}\right)$ followed by D5 $\left(0.058 \mathrm{~h}^{-1}\right)$. These results were reflected in multiplication rates (MR) and doubling times $\left(\mathrm{t}_{\mathrm{d}}\right)$ to be $0.012 \mathrm{~h}^{-1}, 7.87 \mathrm{~h}^{-1}$ for S5 and $0.08 \mathrm{~h}^{-1}, 11.94 \mathrm{~h}^{-1}$ for D5, respectively. The highest generation number was recorded by $\mathrm{S} 5$ and the lowest value was recorded by D5. It was observed that lipid production started during the exponential phase of growth then sharply increased to achieve the maximum values of lipid weight $\left(\mathrm{gl}^{-1}\right)$ and lipid content $(\%)$ during stationary phase after $80,120,96$ and $104 \mathrm{~h}$ of fermentation time for S5, D5, J3 and C9 isolates, where the corresponding values of lipid content were 35.08, 30.06, 36.72 and 37.57, respectively. Vijayakumar et al. (2010) evaluated lipid production of Rhodotorulla glutinis in different carbon sources, between the sources; glucose caused lipid yield and lipid content of $2.43 \mathrm{~g} / \mathrm{l}$ and $23.78 \%$. The present data yielded higher values compared to those reported by Dai et al. (2007) and Easterling et al. (2009) since they found that Rhodoturula glutinis and Rhodosporidium toruloides produced $25 \%$ and $36.6 \%$ lipid respectively using glucose as a carbon sources. Consumed sugar increased gradually to record the highest value by S5 and D5 at $72 \mathrm{~h}$ being 39.63 and $39.73 \mathrm{gl}^{-1}$ and at $96 \mathrm{~h}$ by $\mathrm{J} 3$ being $37.88 \mathrm{gl}^{-1}$, respectively, whereas C9 attained the highest value at $104 \mathrm{~h}\left(38.86 \mathrm{gl}^{-1}\right)$. The corresponding figures of sugar utilization efficiency (SUE \%) and conversion coefficient (CC\%) were $99.09,3.20 \%$ for S5, 99.32, 2.27\% for D5, 94.7, 4.67\% for $\mathrm{J} 3$ and $97.15,5.26 \%$ for $\mathrm{C}$, respectively as shown in Fig. 3. On the other hand when xylose used as a source of carbon, Li et al. (2005) investigated the lipid coefficients of 10 oleaginous yeasts utilizing xylose and showed that Rhodosporidium toruloides had the maximum conversion rate of $10.6 \mathrm{~g}$ of lipid per $100 \mathrm{~g}$ of consumed xylose. It was found that the biomass yield (\%) gradually decreased during the incubation period then slightly increased due to assimilation of lipid content as carbon sources. Lipid synthesis was partially associated with the linear growth phase as well as during stationary phase.

TABLE 3.Growth kinetics of the selected isolates $(\mathrm{S5}, \mathrm{D5}, \mathrm{J3}, \mathrm{C9})$ grown in nitrogenlimited medium (productive medium) at $28-30{ }^{\circ} \mathrm{C}$ during $128 \mathrm{~h}$ under shaking condition.

\begin{tabular}{|c|c|c|c|c|}
\hline \multirow[t]{2}{*}{ Yeast isolates } & \multicolumn{4}{|c|}{ Growth kinetics } \\
\hline & ${ }^{*} \boldsymbol{\mu}\left(\mathbf{h}^{-1}\right)$ & ${ }^{*} t_{d}\left(h^{-1}\right)$ & ${ }^{*} \operatorname{MR}\left(h^{-1}\right)$ & (N) \\
\hline S5 & 0.089 & 7.87 & 0.012 & 2.04 \\
\hline D5 & 0.058 & 11.94 & 0.08 & 1.15 \\
\hline J3 & 0.049 & 14.14 & 0.07 & 1.24 \\
\hline C9 & 0.056 & 12.37 & 0.08 & 1.29 \\
\hline
\end{tabular}

Egypt. J. Microbiol. 49 (2014) 

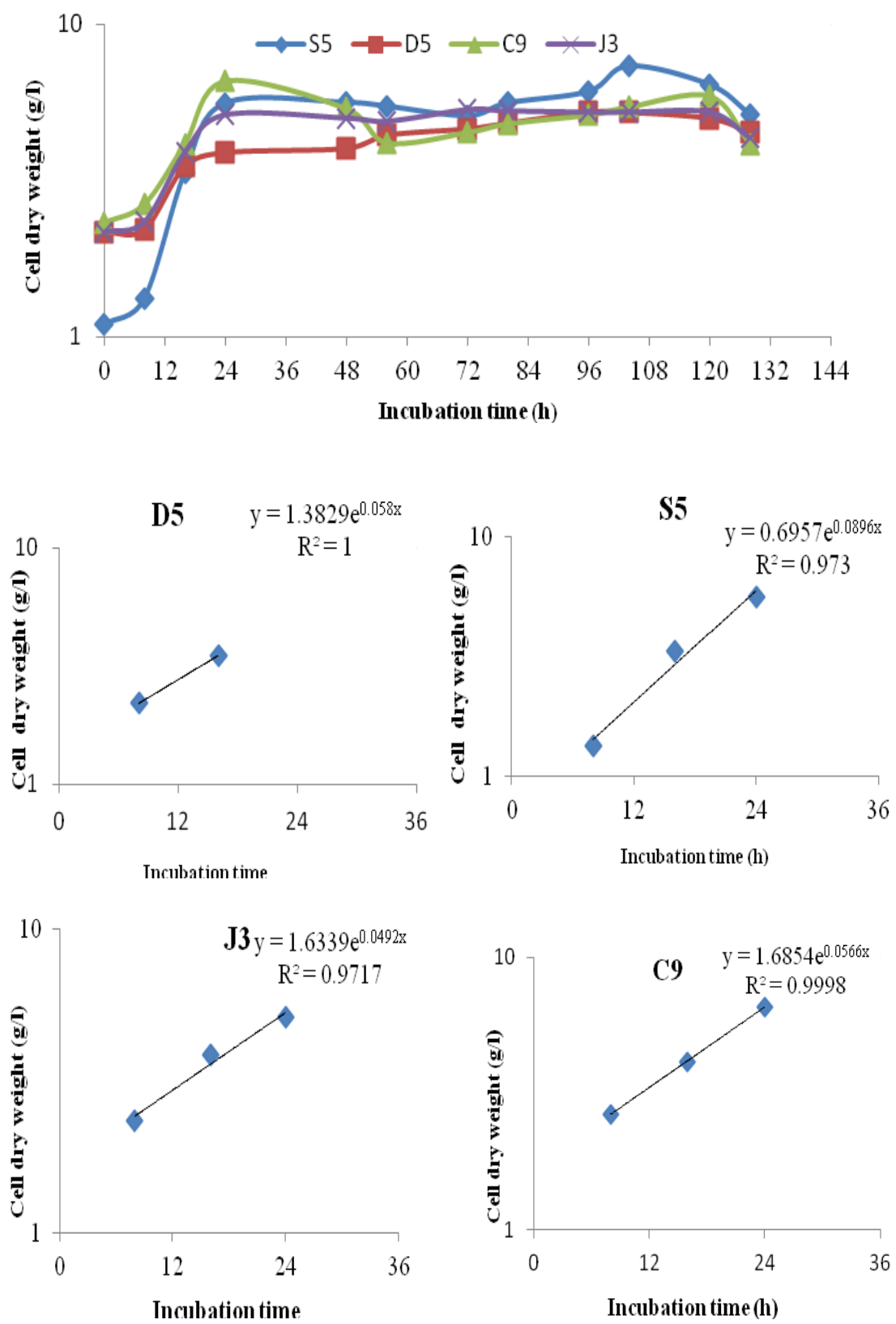

Fig. 2. Growth curve and correlation coefficient between the dry weight of biomass $\left(\mathrm{gl}^{-1}\right)$ and incubation time of the tested isolates $(\mathrm{S5}, \mathrm{D5}, \mathrm{J3}, \mathrm{C9})$ detected using a semi logarithmic scale. 


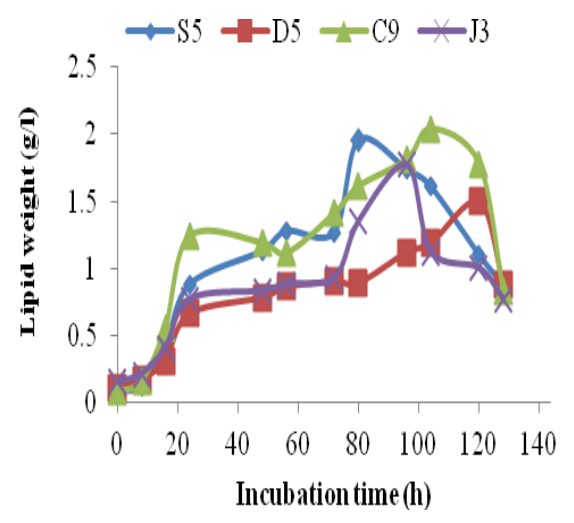

Consumed sugar

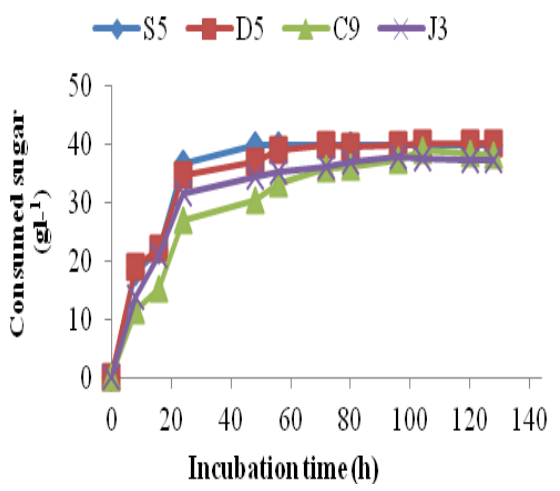

Lipid yield (\%)

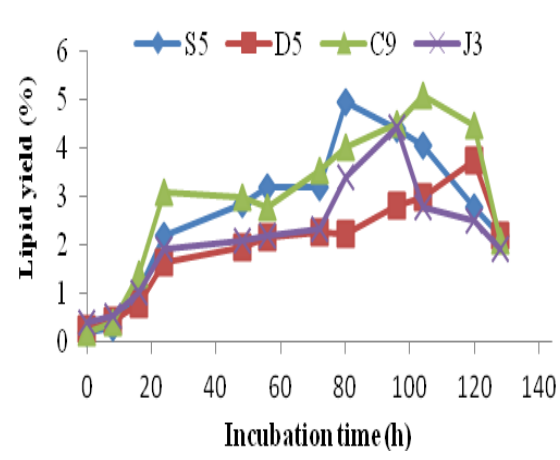

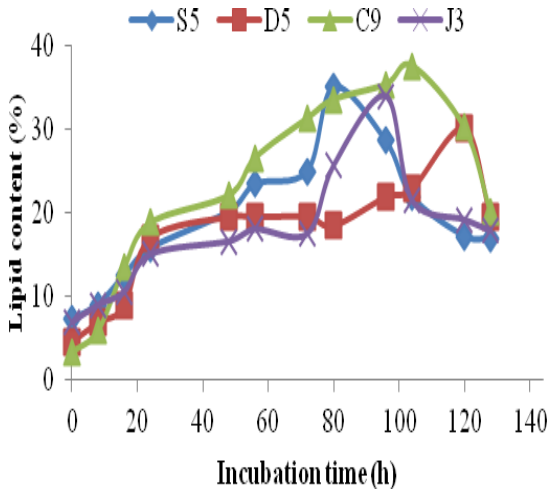

Sugar utilization efficiency (SUE\%)

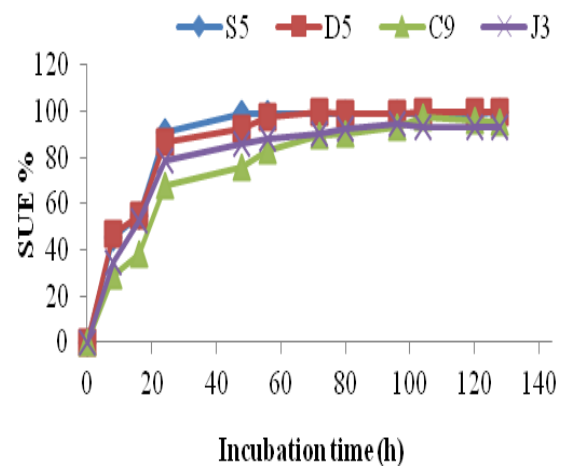

Conversion coefficient (Cc) \%

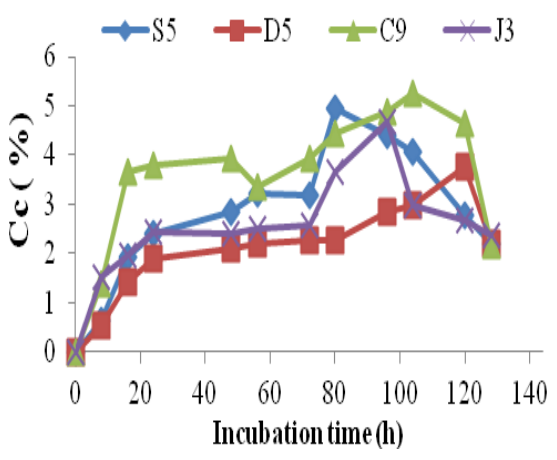

Fig. 3. Growth and lipid production of selected isolates $(\mathrm{S5}, \mathrm{D5}, \mathrm{J3}, \mathrm{C9})$ in production medium (nitrogen-limited medium) during $128 \mathrm{~h}$ using shake flask. 
Fatty acids profile analysis

In this investigation, the four yeast isolates which showed high efficiency to accumulate lipid droplets, were used to detect fatty acid profile. Table 4 shows that the fatty acids profiles for isolates S5, D5, C9 and J3, including triacylglycerols (TAG) palmitic acid (C16:0), stearic acid (C18:0), oleic acid (C18:1) and linoleic acid (C18:2) similar to those of vegetable oils. To obtain a biodiesel with appropriate quality characteristics, an appropriate ratio between saturated and unsaturated fatty acids should be maintained (Knothe, 2005). Regarding the saturated and unsaturated fatty acids composition of S5,D5,C9 and J3 ,data revealed that saturated fatty acids were $30.33 \%, 27.55 \%, 23.95 \%$ and $35.83 \%$ while total of un saturated fatty acid were $67.57 \%, 71.43 \%, 43.61 \%$ and $40.66 \%$ respectively. The total fatty acid methyl esters $\mathrm{C} 16$ and $\mathrm{C} 18$ were $92.68 \%$ and $94.45 \%$ for isolates S5 and D5, but these proportions were sharply decreased to $64.36 \%$ and $67.49 \%$ for both C9 and $\mathrm{J} 3$ isolates, respectively (Table 4 and Fig. 4). It was also observed that the highest dominant fatty acid among the fatty acids profile of the 4 isolates was oleic acid (C18:1) with content ranging between $29.14 \%$ and $55.69 \%$, followed by palmitic acid (C16:0) with content ranging between $16.08 \%$ to $31.52 \%$ among the 4 isolates. In addition, palmitoleic acid (C16:1) which was $13.75 \%, 15.74 \%$ and $8.08 \%$, as one of the main products with S5, D5 and C9 whereas isolate J3 produced negligible amounts of this fatty acid. These data correspond with those obtained by Li et al., (2010) who reported that the fatty acids from Rhodotorula mucilaginosa TJY15a were mainly composed of palmitic acid (C16:0), palmitoleic acid (C16:1), stearic acid (C18:0), oleic acid (C18:1) and linolenic acid (C18:2). Whereas Zhu et al. (2008) reported that the lipid of yeast Trichosporon fermentans mainly contains palmitic acid, stearic acid, oleic acid and linolenic acid and the unsaturated fatty acids amount to about $64 \%$ of the total fatty acids which is similar to those of plant oil. In this respect, Bajpai \& Tyagi (2006) found that soybean, cotton seed and rapeseed oil contained stearic acid (C18:0) ranging from $2.32 \%-4.67 \%$. Therefore, based on fatty acids profile data, the microbial lipids of D5 and S5 which are highly rich in appropriate fatty acids could be used as a promising alternative feed stock for biodiesel production.

Genetic analysis of oleaginous yeasts

The selected isolates (D5 and S5) that showed the most potential ability in producing lipids and have the similar fatty acid profile to plant oils abundant in low degree unsaturated long chain fatty acid (C18:1) and saturated long chain fatty acids (C16:0) \} were identified using a molecular taxonomic approach. BLAST analysis of the 26S rRNA gene sequence of the yeast isolates D5\&S5 were revealed to be a perfect match with that of Pichia kudriavzevii APKU-5 and Candida tropicalis ssm-39 type strains, respectively. Alignment and comparison of the 26S sequence of the D5\& S5 isolates to the published 26S rRNA sequences belonging to reference strains of phenotypically close species of Pichia and Candida confirmed the 99\% similarity. Therefore, the isolates D5 and S5 were identified as Pichia kudriavzevii and Candidda tropicalis, respectively, (See Fig. 5). 
TABLE 4. Fatty acids profile of the lipids accumulated in yeast isolates $(\mathrm{C} 9, \mathrm{S5}, \mathrm{J3}$, D5) grown on $\mathbf{N}$-limited medium.

\begin{tabular}{|c|c|c|c|c|c|}
\hline \multirow{2}{*}{$\begin{array}{c}\text { Type of fatty } \\
\text { acids } \\
\end{array}$} & \multirow{2}{*}{$\begin{array}{c}\text { Fatty acid } \\
\text { profile }\end{array}$} & \multicolumn{4}{|c|}{ Fatty acid $(\%, w / w$ TFA $*)$} \\
\hline & & S5 & D5 & C9 & $\mathbf{J 3}$ \\
\hline \multirow{8}{*}{$\begin{array}{l}\text { Saturated } \\
\text { fatty acids }\end{array}$} & $\frac{\text { Capric acid }}{(\mathrm{C} 10: 0)}$ & 0.11 & nd & nd & nd \\
\hline & $\begin{array}{l}\text { Tridecylic acid } \\
\text { (C13:0) }\end{array}$ & 0.18 & nd & nd & nd \\
\hline & $\begin{array}{l}\text { Mysteric acid } \\
(\mathrm{C} 14: 0)\end{array}$ & 0.38 & 0.46 & 1.43 & nd \\
\hline & $\begin{array}{l}\text { Pentadecanoic } \\
\text { acid (C15:0) }\end{array}$ & nd & 0.03 & 1.17 & nd \\
\hline & $\begin{array}{l}\text { Palmitic acid } \\
\text { (C16:0) }\end{array}$ & 21.89 & 20.70 & 16.08 & 31.52 \\
\hline & $\frac{\text { Margaric acid }}{(\mathrm{C} 17: 0)}$ & 4.55 & 4.04 & 0.60 & nd \\
\hline & $\begin{array}{l}\text { Stearic acid } \\
(\mathrm{C} 18: 0)\end{array}$ & 3.22 & 2.32 & 4.67 & 4.31 \\
\hline & $\begin{array}{l}\text { Total saturated } \\
\text { fatty acids }\end{array}$ & 30.33 & 27.55 & 23.95 & 35.83 \\
\hline \multirow{4}{*}{$\begin{array}{l}\text { Unsaturated } \\
\text { fatty acids }\end{array}$} & $\begin{array}{l}\text { Palmetoleic acid } \\
\text { (C16:1) }\end{array}$ & 13.75 & 15.74 & 8.08 & nd \\
\hline & $\begin{array}{l}\text { Oleic acid } \\
(\mathrm{C} 18: 1)\end{array}$ & 53.82 & 55.69 & 27.85 & 29.14 \\
\hline & $\begin{array}{l}\text { Linoleic acid } \\
(\mathrm{C} 18: 2)\end{array}$ & nd & nd & 7.68 & 11.52 \\
\hline & $\begin{array}{l}\text { Total unsaturated } \\
\text { fatty acids }\end{array}$ & 67.57 & 71.43 & 43.61 & 40.66 \\
\hline $\begin{array}{l}\text { Poly } \\
\text { unsaturated } \\
\text { fatty acid }\end{array}$ & $\frac{\text { Arachidic acid }}{\left(\mathrm{C}_{20} \mathrm{H}_{30} \mathrm{O}_{2}\right)}$ & nd & 2.09 & nd & nd \\
\hline \multicolumn{2}{|c|}{$\begin{array}{l}\text { Total C16 and C18 methyl ester } \\
\text { yield \% }\end{array}$} & 92.68 & 94.45 & 64.36 & 67.49 \\
\hline
\end{tabular}

TFA ${ }^{*}$ : Total fatty acids

nd: not detected

\section{Conclusion}

Data obtained in this study deduced that isolated Pichia kudriavzevii D5 and Candidda tropicalis S5 could be elected as promising alternative feedstock for biodiesel production. The parameters are depending on total $\mathrm{C} 16$ and $\mathrm{C} 18$ methylesters yield which were found in high proportion among both S5 and D5 (92.68\% and $94.45 \%$ respectively). Additionally to that, the data of fatty acids profile analysis demonstrated that the ratio of saturated and unsaturated fatty acids in the produced triacylglycerides of yeast isolates were $30.33 \%, 27.55 \%$ for saturated fatty acids while unsaturated fatty acid were $67.57 \%$ and $71.43 \%$ for both strains, respectively. 


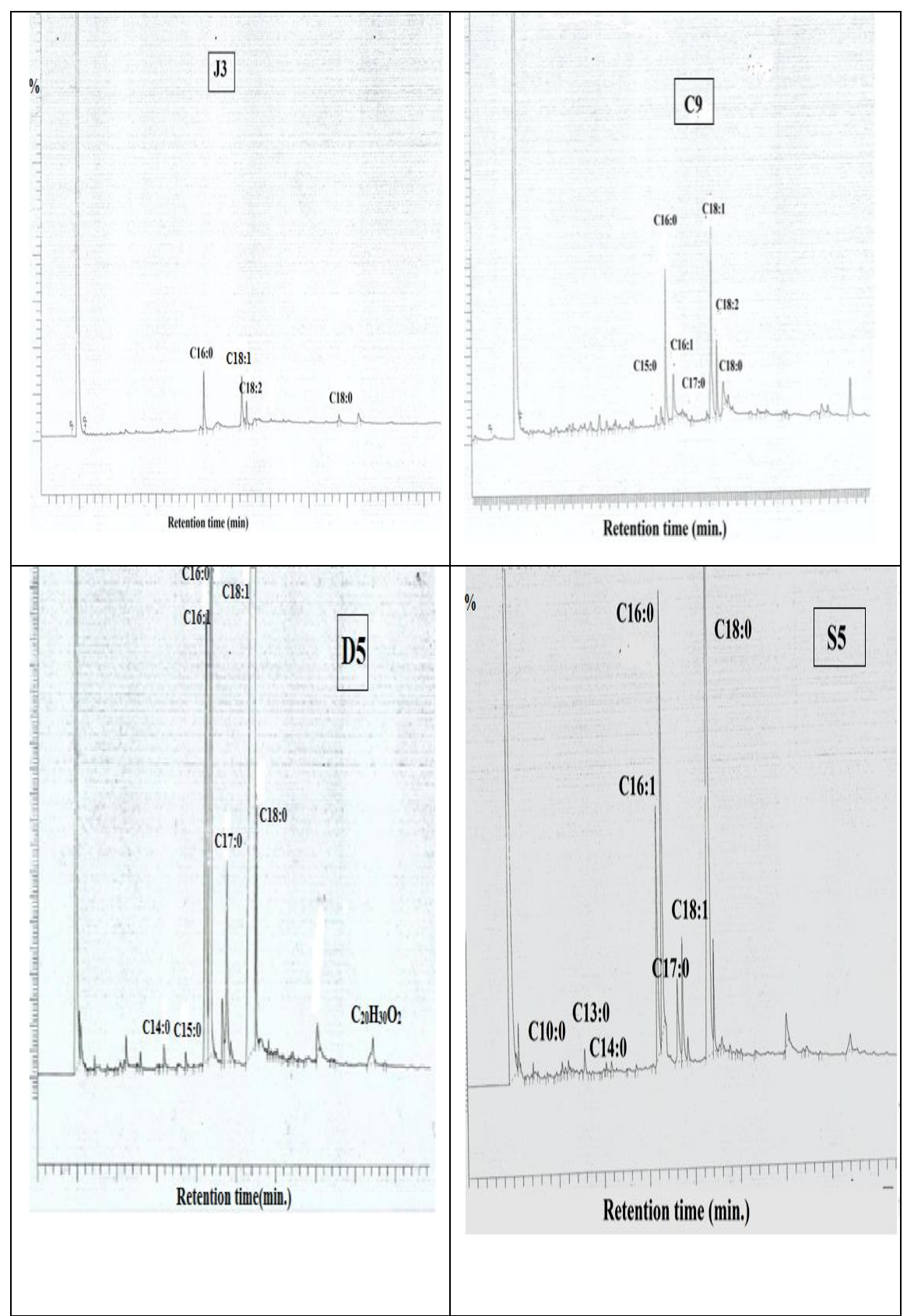

Fig. 4. Fatty acids profile of selected isolates D5, S5, C9, and J3 by Gas chromatography. 


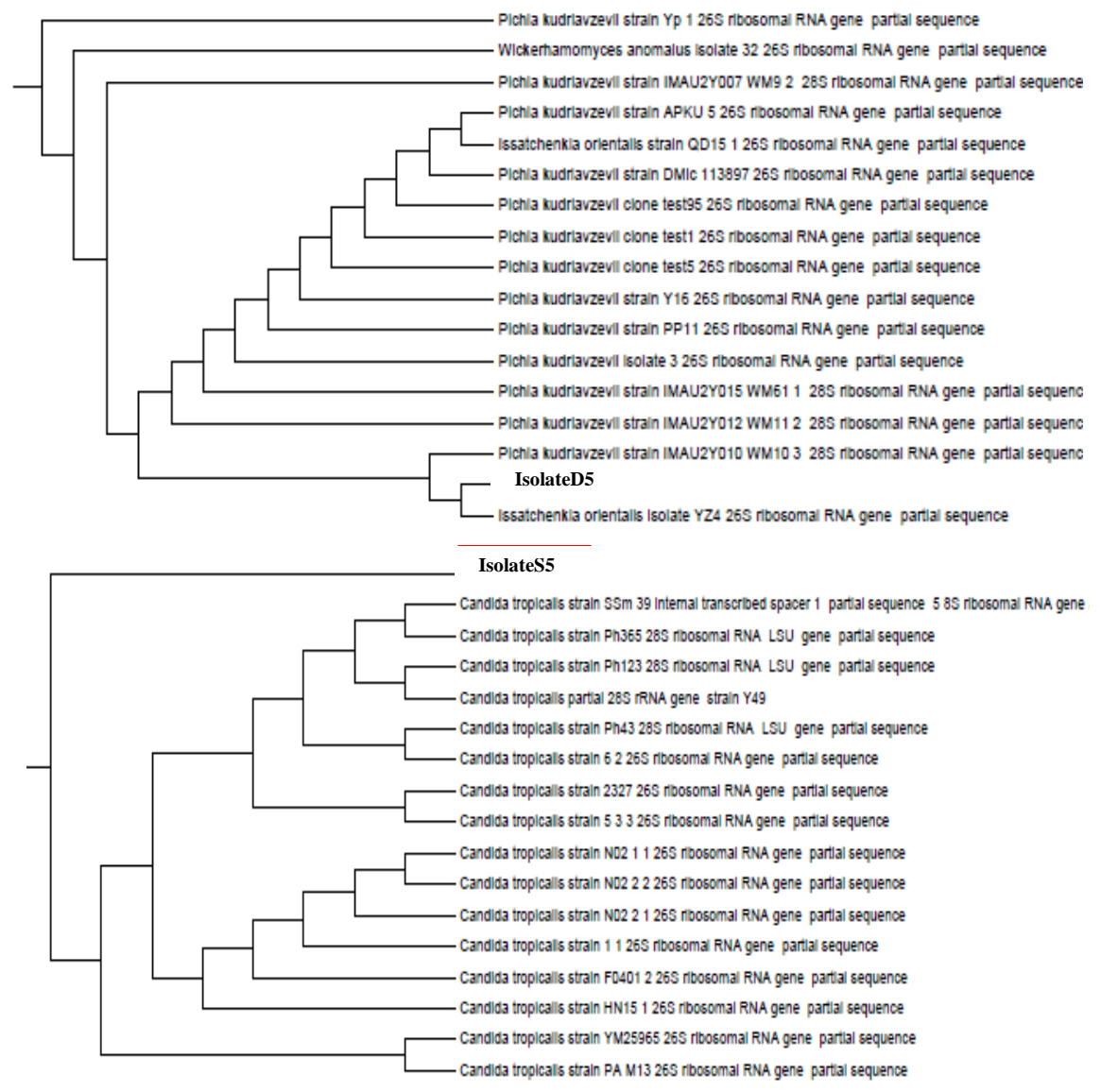

Fig. 5. Phylogenetic trees based on the sequences of the D1/D2 domain of the LSU rRNA gene, showing position of the isolates D5\&S5 with closely related species.

\section{References}

Altschul, S.F., Madden, T.L., Schäffer, A.A., Zhang, J., Zhang, Z., Miller, W. and Lipman, D.J. (1997) Gapped BLAST and PSI-BLAST : a new generation of protein database search programs. Nucleic Acids Res. 25, 3389-402.

Amaretti, A., Raimondi, S., Sala, M., Roncaglia, L., Lucia, D.M., Leonardi, A. and Rossi, M. (2010) Single cell oil of cold adapted oleaginous yeast Rhodotorula glacialis DBVPG 4785. Microbial Cell Factories, 23, 59-73.

Angerbauer, C., Siebenhofer, M., Mittelbach, M. and Guebitz, G.M. (2008) Conversion of sewage sludge into lipids by Lipomyce starkeyi for biodiesel production. Biores. Technol. 99, 3051-3056.

Egypt. J. Microbiol. 49 (2014) 
Azócar, L., Ciudad, G., Heipieper, H.J. and Navia, R. (2010) Biotechnological processes for biodiesel production using alternative oils. Applied Microbiology and Biotechnology, 88 (3), 621-636.

Bajpai, V. and Tyagi, V.K. (2006) Biodiesel: source, production, composition, properties and its benefits. Journal of Oleo Science, 55(10), 487-502.

Beopoulos, A., Cescut, J., Haddouche, R., Uribelarrea, J.L., Molina Jouve, C. and Nicaud, J.M. (2009) Yarrowria lipolytica as a model forbio-oil production. Prog. Lipid Res. 48, 375-387.

Cao, X.F., Xie, H.B., Wu, Z.L., Shen, H.W. and Jing, B. (2012) Phase-switching homogeneous catalysis for clean production of biodiesel and glycerol from soybean and microbial lipids. Chem Cat Chem. 4, 1272-1278.

Czabany, T., Athenstaedt, K. and Daum, G. (2007) Synthesis, storage and degradation of neutral lipids in yeast, Biochim. Biophys. Acta, 1771, 299-309.

Dai, C., Tao, J., Xie, F., Dai, Y.J. and Zhao. M. (2007) Biodiesel generation oleaginous yeast Rhodotorula glutinis with xylose assimilating capacity, African Journal of Biotechnology, China, 2130-2134.

Easterling, E.R, French, W.T., Hernandez, R. and Licha, M. (2009) The effect of glycerol as a sole and secondary substrate on the growth and fatty acid composition of Rodotorula glutinis. Bioresour. Technol. 100, 356-361.

Escobar, J.C., Lora, E.S., Venturini, O.J., Yanez, E.E., Castillo, E.F. and Almazan, O. (2009) Biofuels: environment, technology and food security. Renew. Sust. Energ. Rev. 13,1275-1287.

Fedosov, S.N., Brask, J., Pedersen, A.K., Nordblad, M., Woodley, J.M. and Xu, X.B. (2013) Kinetic model of biodiesel production using immobilized lipase Candida antarctica lipase B. J. Mol. Catal. B: Enzym, 85-86, 156-168.

Ferella, F., Di Celso, G.M., De Michelis, I., Stanisci, V. and Veglio, F. (2010) Optimization of the transesterification reaction in biodiesel production. Fuel, 89, 36-42.

Fisher (1970) “Statistical Methods for Research Workers". 14 $4^{\text {th }}$ ed. New York: Hafner.

Folch, J., Lees, M. and Sloane-Stanley, G.H. (1957) A simple method for the isolation and purification of total lipids from animal tissues. Journal of Biological Chemistry, 226, 497-509.

Granger, L.M., Perlot, P., Goma, G. and Pareilleux, A. (1993) Efficiency of fatty acid synthesis by oleaginousyeasts: Prediction of yield and fatty acid cell content from consumed C/N ratio by a simple method. Biotechnol. Bioeng. 42, 1151-1156.

Knothe, G. (2005) Dependence of biodiesel fuel properties on the structure of fatty acid alkyl esters. Fuel Processing Technology, 86, 1059-1070. 
Kurtzman, C.P. and Robnett, C. J. (1998) Identification and phylogeny of ascomycetous yeasts from analysis of nuclear large subunit (26S) ribosomal DNA partial sequences. Antonie van Leeuwenhoek, 73, 331-371

Li, Y.H., Liu, B., Sun, Y., Zhao, Z.B. and Bai, F.W. (2005) Screening of oleaginous yeasts forbroad-spectrum carbohydrates assimilation capacity, China Biotechnol. 25, $39-43$

Li, Q., Du, W. and Liu, D. (2008) Perspective of microbial oils for biodiesel production. Applied. Microbiology and Biotechnology, 80, 749-756.

Li, M., Liu, G.L. and Chi, Z. M. (2010) Single cell oil production from hydrolysate of cassava by marine-derived yeast Rhodotorula mucilaginosa TJY15. Biomass Bioner. 34, 101-107.

Liu, Z.Y., Wang, G.C. and Zhou, B.C. (2008) Effect of iron on growth and lipid accumulation in Chlorella vulgaris. Biores. Technol. 99 (11), 4717-4722.

Liu, F., Wang, L., Sun, Q., Zhu, L., Meng, X. and Xiao, F.S. (2012) Transesterification catalyzed by ionic liquids on super hydrophobic mesoporous polymers heterogeneous catalysts that are faster than homogeneous catalysts. J. Am. Chem. Soc. 134, 1694816950.

Liu, B. and Zhao, Z.K. (2007) Biodiesel production by direct methanolysis of oleaginous microbial biomass. J. Chem. Technol. Biotechnol. 82, 775-780.

Luddy, F.E., Beerford, R.A. and Riemen Schneider, R.W. (1960) Direction conversion of lipid component to their fatty acid methyl ester. J. Amer. Oil Chem. Soc. 37, 447451.

Meng, X., Yang, J.M., Xu, X., Zhang, L., Nie, Q.J. and Xian, M. (2009) Biodiesel production from oleaginous microorganisms. Renew. Energy, 34(1), 1-5.

Pan, L.X., Yang, D.F., Shao, L., Li, W., Chen, G.G. and Liang Z.Q. (2009) Isolation of oleaginous yeast from the soil and studies of their lipid-producing capacities, Food Technology and Biotechnology, 47, 215-220.

Papanikolaou, S., Komaitis, M. and Aggelis, G. (2004) Single cell oil (SCO) production by Mortierella isabellina grown on high-sugar content media. Biores. Technol. 95, 287-91.

Ratledge, C. and Wynn, J.P. (2002) The biochemistry and molecular biology of lipid accumulation in oleaginous microorganisms, Adv. Appl. Microbiol. 51, 1-44.

Rossi, M., Buzzini, P., Cordisco, L., Amaretti, A., Sala, M., Raimondi, S., Ponzoni, C., Pagnoni, U.M. and Matteuzzi, D. (2009) Growth, lipid accumulation, and fatty acid composition in obligate psychrophilic, facultative psychrophilic and mesophilic yeasts. FEMS. Microbiol. Ecol. 69, 363-372.

Seki, T., Eon, H. and Dewy, R. (1985) Construction of killer wine yeast strains. Applied and Environmental, 49 (5), 1211-1215.

Egypt. J. Microbiol. 49 (2014) 
Thakur, M.S., Prapulla, S.G. and Karanth, N.G. (1988) Microscopic observation of sudan black B staining to monitor lipid production by Microbes. Journal of Chemical Technology and Biotechnology, 42,129-134.

Vijayakumar, S., Kumutha, K., Santhana K. and Gopal, H. (2010) "Effect of Carbon Sources on Lipid and Biomass Production by Oleaginous Yeast Cultures", Tamil Nadu Agriculture University, Coimbatore, pp.1-3.

Xu, J., Du, W., Zhao, X., Zhang, G. and Liu, D. (2013) Microbial oil production from various carbon sources and its use for biodiesel preparation. Biofuels, Bioprod. Bioref. Rev. 10, 1-13.

Yen, H.W. and Yang, Y.C. (2012) The effects of irradiation and microfiltration on the cells growing and total lipids production in the cultivation of Rhodotorula glutinis. Biores. Technol., 107, 539-541.

Yoo, C., Jun, S.Y., Lee, J.Y., Ahn, C.Y. and Oh, H.M. (2010) Selection of microalgae for lipid production under high levels carbon dioxide. Biores. Technol. 101:71-74.

Zhu, L.Y., Zong, M.H. and Wu H. (2008) Efficient lipid production with Trichosporon fermentans and its use for biodiesel preparation. Biores. Technol. 99, 7881-7885.

(Received 20 / 10/2014;

accepted 23 / 11/ 2014) 


\section{تقييم الخمائر المنتجة لليبيدات لإنتاج الديزل الحيوى \\ داليا مصطفى محمد، ايناس عبد التواب حسن" ، فاطمة حلمى عبد الظاهر، حسين

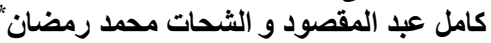

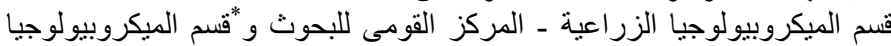

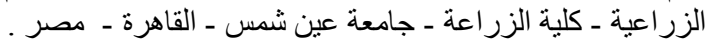

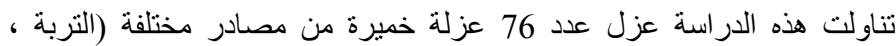

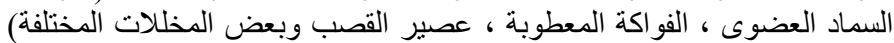

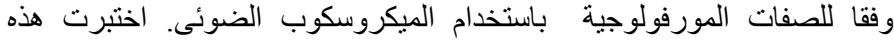

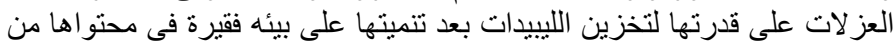

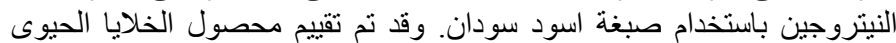

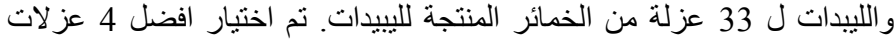

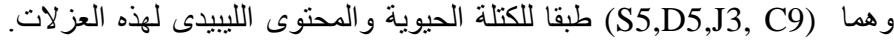

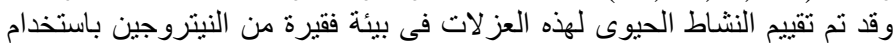

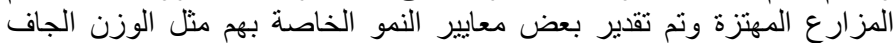

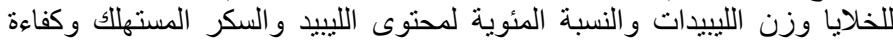

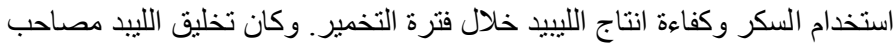

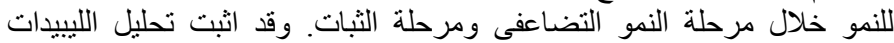

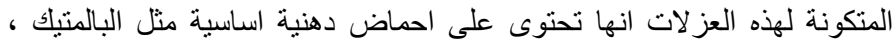

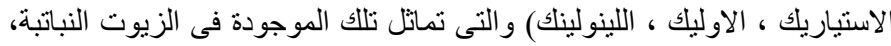

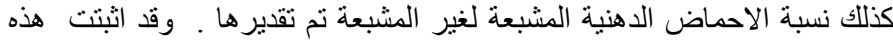

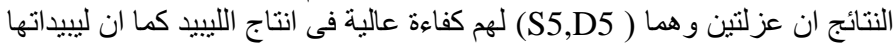

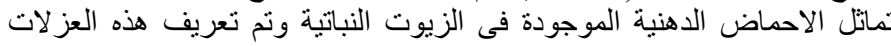

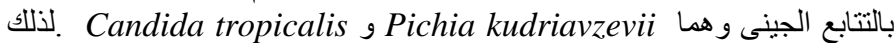
تعتبر هذه السلالات مناسبة لاستخدامها فى انتاج الديزل الحيوى. 